\title{
Relinquishment criteria verification: quality assurance/quality control using unmanned aerial vehicles
}

\author{
PL Jones Flinders Power, Australia \\ C Franklin CLD Mining, Australia
}

\begin{abstract}
Leigh Creek Coalfield is located approximately $550 \mathrm{~km}$ north of Adelaide, in an arid area of South Australia. It was formerly operated by the state-owned Electricity Trust and has over 70 years of open cut mining history. The coal was hauled $250 \mathrm{~km}$ south by rail to fuel the Port Augusta Power Stations, once producing up to $40 \%$ of South Australia's electricity demand. The mine, currently under Flinders Power control, was leased in 2000, and coal mining operations ceased in November 2015 due to the closure of the Port Augusta Power Stations. A swift decision to close the mine, with partially built landforms and legacy issues from early mining practices, created rehabilitation challenges. The mine closure plan identified the major risks as spontaneous combustion of the in-pit and surface waste dumps, public safety and surface water control. A comprehensive mine closure plan and set of relinquishment criteria were developed and agreed with the regulator. The challenge was to demonstrate to the regulator the successful completion and achievement of the relinquishment criteria.

Procedural control, timely data capture, effective quality assurance/quality control (QA/QC) and independent verification, are critical components in demonstrating completion of mine closure relinquishment criteria. However, these components are not necessarily second nature to mining operators.

The Leigh Creek closure team developed an innovative solution, the Inspection Test Plan (ITP), utilising stateof-the-art unmanned aerial vehicle (UAV) technology it captures all the critical components in one package. Presented in the paper is the Leigh Creek ITP, the operational implementation of the ITP, and how the ITP was successfully employed to achieve verification of the mine closure relinquishment criteria at Leigh Creek.
\end{abstract}

Key components of the ITP include:

- Design approval and operational implementation procedural control, including hold points.

- Inert material rehabilitation cover thickness verification against design using UAV technology.

- Digital elevation model created using UAV survey data for watershed analysis of individual constructed evaporation ponds, with verification against design criteria.

- Real-time onsite material sampling program including laboratory confirmation.

- Thermal imaging data, photographic timeline and operational response to non-compliance.

- Structured design component sign-off and independent verification process.

Some operational statistics from the successfully completed Leigh Creek mine rehabilitation project include:

- 14 million loose cubic metres of earthworks including 4 million loose cubic metres of cover placed.

- 65,000 machine hours and over 2,500 km flown with a UAV.

- 480 surface water sub-catchments created and assessed.

- 293 evaporation areas totalling 2,100 hectares created.

- $153 \mathrm{~km}$ of surface water bunds created.

Keywords: relinquishment, verification, quality control, unmanned aerial vehicle, rehabilitation 


\section{Introduction}

Leigh Creek Coalfield is located approximately $550 \mathrm{~km}$ north of Adelaide, in an arid area of South Australia. The site has over 100 years of mining history including 70 years of open cut. In June 2015, the closure of the Flinders business, incorporating the Leigh Creek Coalfield, the connecting rail line and the Port Augusta Power Stations it supplied was announced. Leigh Creek Coalfield ceased mining in November 2015.

The mine closure plan identified the major risks as spontaneous combustion of the in-pit and surface waste dumps, public safety and surface water control. The key rehabilitation strategies were to control the risk of spontaneous combustion to 'as low as is reasonably practicable' (ALARP) by reprofiling 'at-risk' waste dump slope angles followed by applying a cover of inert material, constructing a network of surface water controls and installation of safety bunds around the pit voids.

The mine closure works program included 14 million loose cubic metres of earthworks, 4 million loose cubic metres of inert cover material placed and the creation of 480 surface water sub-catchments.

\section{$2 \quad$ Mine closure plan development}

Leigh Creek Coalfield was previously state-owned and operated. It had a unique regulatory position with the state of South Australia. Unlike other mines in South Australia, the site did not have a formal plan for environmental protection and rehabilitation (PEPR) or mine closure plan (MCP) with the Mining Regulation Branch of the Department for State Development (DSD), now the Department for Energy and Mining (DEM).

At the time of closure, rehabilitation requirements were captured in the Approved Mine Development Plan (AMDP) documents developed at the time of privatisation, as detailed below. These AMDP documents were brief in nature, and did not adequately address the risks, or list the closure requirements in specific detail.

"Coalfield operations are principally regulated by the Chief Inspector of Mines appointed under the Mines and Works Inspection Act 1920 (SA) (MWIA).

This mine closure document is a development program applying to the Leigh Creek Coalfield, for purposes of Regulation 9 of the Mines and Works Inspection Regulations 2013 (SA). It replaces Approved Development Plans numbered AMDP 00/41 and AMDP $00 / 42$ in so far as they relate to mine closure and mine rehabilitation of the Leigh Creek Coalfield." Flinders Power (2018a)

The development of the formal mine closure plan and related closure risk register by geographic domains has been a significant undertaking by the Flinders Power team, necessarily completed in a short timeline, due to the unforeseen closure announcement.

Risk workshops with the relevant South Australian Government regulatory stakeholders were held. The site was separated into geographic domains, with different risk profiles, as displayed in Figure 1. An integrated risk management approach was used to address the interrelated public safety, environmental, and heritage risks present in each domain. Analytical thinking and a strategic focus were employed to achieve an outcome that ultimately both the regulators and the company could endorse.

The site was divided into a grid and each sector of the grid was allotted a map number as displayed in Figure 2. Detailed map design notes were prepared for each sector. The detailed 3D designs to capture the endorsed domain specific rehabilitation elements for each sector were all included in each map design note. The map design notes were submitted as an appendix to the MCP for review and endorsement by the regulator as part of the approval process. The notes were a very important tool, especially in presenting a contextual view of the hundreds of surface water control features. 


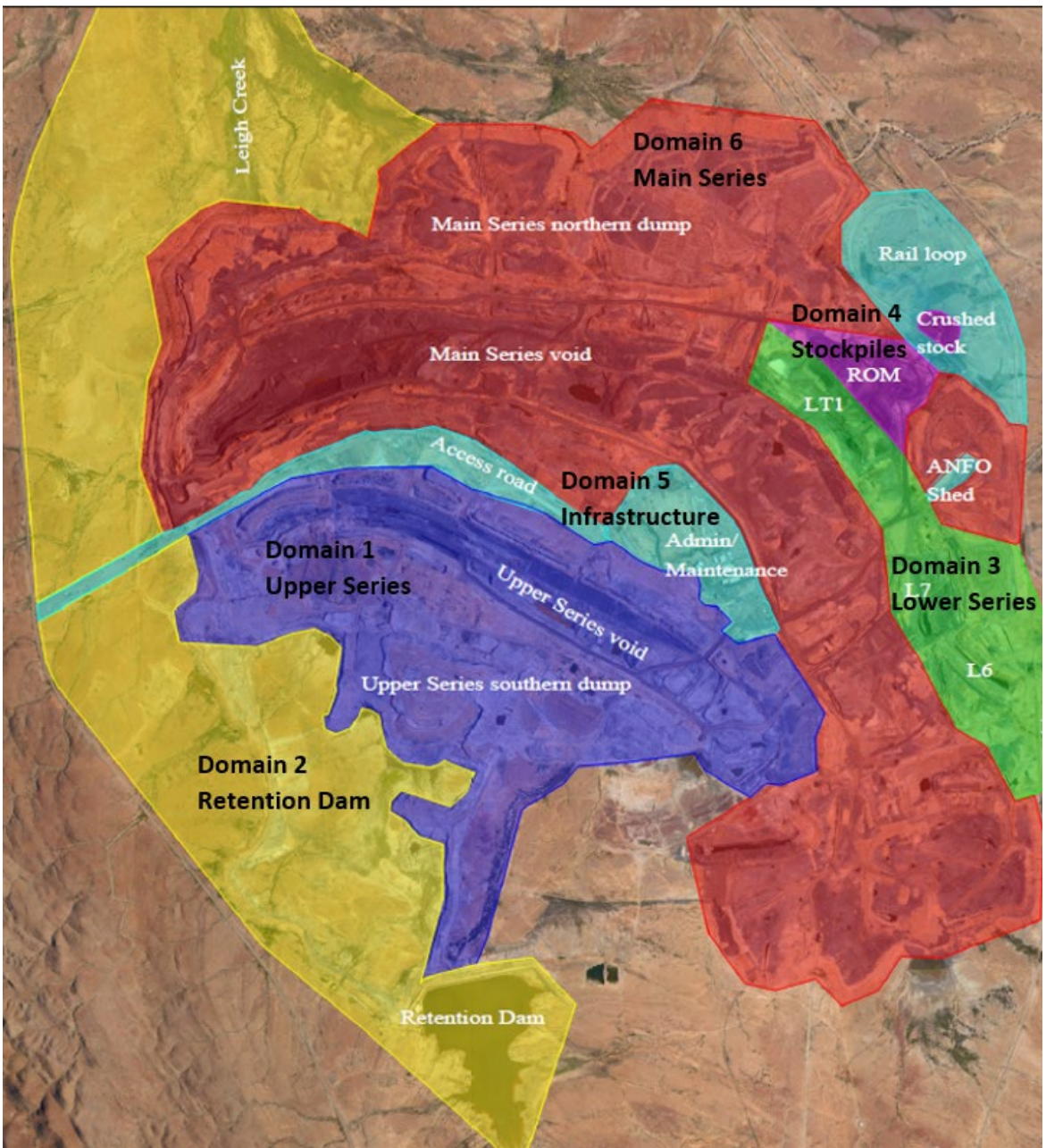

\section{Figure 1 Leigh Creek mine closure domains}

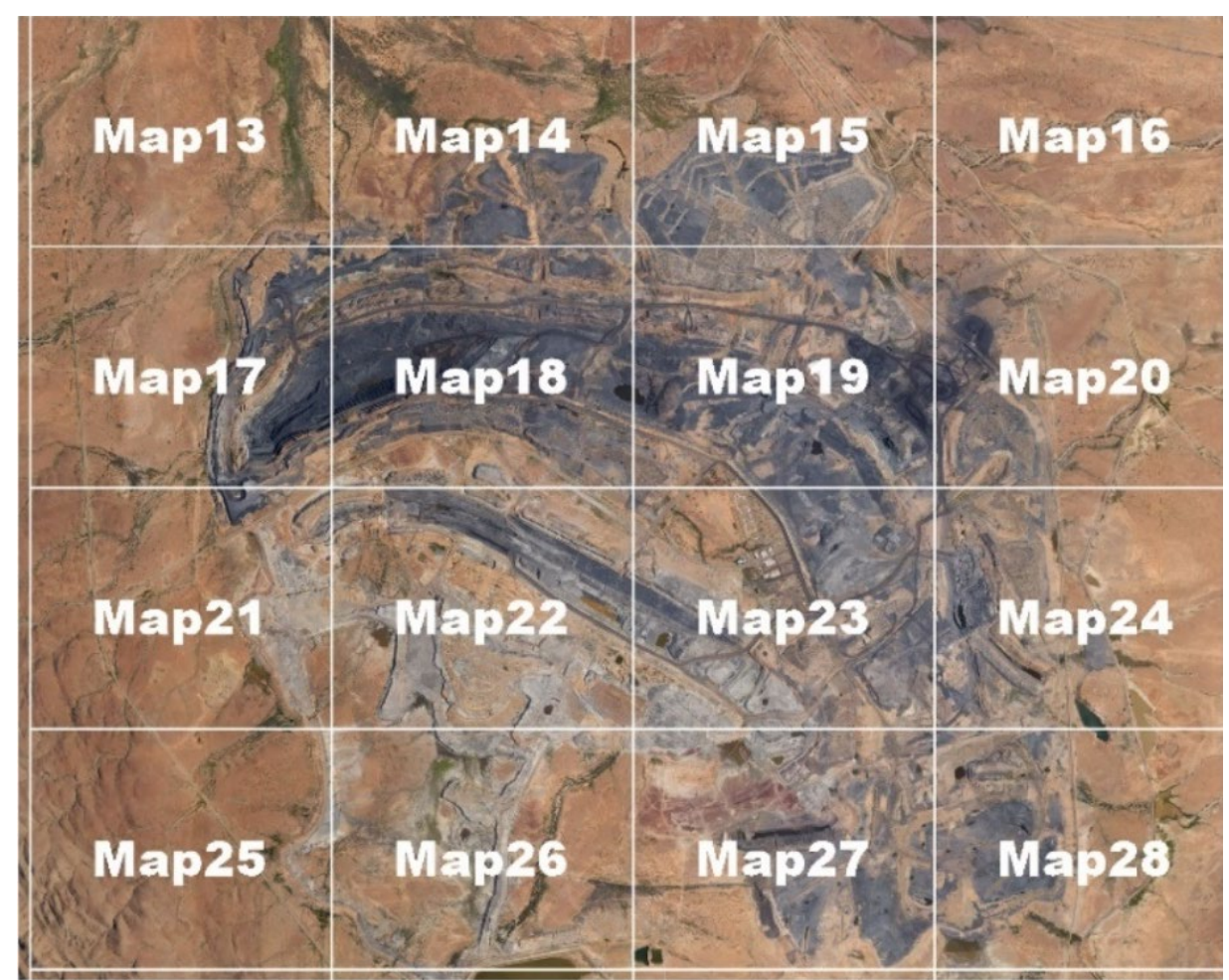

Figure 2 Leigh Creek mine closure map notes grid 


\section{Closure relinquishment criteria}

The preparation/agreement of the mine closure relinquishment completion criteria was an integral part of the MCP development. It was a challenging process for both Flinders Power and the regulators, each party had a different perspective, and the task of accurately capturing the agreed criteria is complex. Many versions of the relinquishment criteria template were reviewed before final agreement was reached.

Every identifiable risk on each of the domain risk registers was captured by one of the domain specific closure relinquishment criteria. A relinquishment completion criteria objective and objective measurement criteria for each criterion was negotiated, including what would be measured and importantly the form of measurement.

To gain regulatory endorsement and close out of relinquishment completion criteria it was critical that the objective measurement criteria was clear to both the regulators and Flinders Power. The criteria needed to accurately capture the requirement, and be concise, measurable and achievable in a realistic time frame.

For a large number of the Leigh Creek relinquishment completion criteria the objective was addressed by implementation of the approved rehabilitation bulk earthworks and surface water control designs as detailed in the map design notes. The objective, objective measurement criteria and form of measurement for an individual closure relinquishment criterion (D6-MC09) is illustrated below, as an example.

"The 'objective' for D6-MCO9 is: Spontaneous Combustion risks are managed to ALARP post lease transfer via at risk pit areas rehabilitated for spontaneous combustion control as per the designs.

The 'objective measurement criteria' for D6-MC09 is: Verification by an independent, suitably qualified person confirms that at-risk pit areas in Domain 6 have been rehabilitated according to relevant designs.

LCK Map 17 Design Notes, LCK Map 18 Design Notes, LCK Map 19 Design Notes, LCK Map 23 Design Notes.

'What will be measured and form of measurement' for D6-MC09 is: Report by an independent, suitably qualified FP engaged expert, using all available data (including $Q A / Q C$ records and surveys) confirms rehabilitation treatment of at-risk pit areas (including surface water features and bunds) in Domain 6 is to design." Flinders Power (2018b)

\section{$4 \quad$ Independent verification}

Mike Slight was engaged as independent verifier for the closure program. Mike is the former chair of the Mining Rehabilitation Fund advisory panel (Department of Mines, Industry Regulation and Safety of Western Australia) and is a former mine manager with many years' experience in mine closure and rehabilitation. With his background and experience he was eminently qualified for the role, and consequently appointed independent verifier by both the State Regulator and Flinders Power.

The challenge as recognised by Flinders Power was how to operationally control the Leigh Creek rehabilitation program onsite to ensure that:

- The mine closure bulk earthworks and surface water control works are completed to design.

- The cover material placed in each location meets the design requirements.

- The required quality assurance/quality control (QA/QC) data is captured in a timely manner along the way.

Additionally, how to present large volumes of data to the independent verifier in a format and level of detail that would be required to approve the design implementation and verify compliance. 


\section{$5 \quad$ Inspection test plan}

To address this need, the Leigh Creek closure team developed an innovative solution that utilises state-ofthe-art unmanned aerial vehicle (UAV) technology and captures all these components in one practical package called an Inspection Test Plan (ITP).

Procedural control, timely data capture, effective $Q A / Q C$ and independent verification, are critical components in demonstrating completion of mine closure relinquishment criteria. However, these components are not necessarily second nature to mining operators. One of the key steps in the ITP development was the inclusion of key onsite personnel in the design process. This enabled a practical implementable solution to be developed that was understood and very importantly supported by the operational team.

The ITP structure was developed to control the process and collect the required data from each individual design for initial verification onsite, followed by verification by the approved independent verifier. The ITP provided control points at various stages of each work package to verify that work completed was aligned with design specifications.

Elements captured by the ITP process included:

- Design approval and operational implementation procedural control, including hold points.

- Inert material rehabilitation cover thickness verification against design using UAV technology.

- Digital elevation model created using UAV survey data for watershed analysis of individual constructed evaporation ponds, with verification against design criteria.

- Real-time onsite material sampling program including laboratory confirmation.

- Thermal imaging data, photographic timeline and operational response to non-compliance.

- Structured design component sign-off and independent verification process.

The ITP process is a central database of information that collates all aspects of the project, including documentation, responsibilities of personnel, schedules and operations, and arranges this into a logical sequence of events. The purpose of the ITP was to develop a documented procedure that recorded all inspection and testing requirements relevant to the delivery of the project. This ensured a progressive approach to quality control was adopted.

Individual ITP work packages were developed for each bulk earthwork design and each surface water subcatchment design. At completion of each design there was a range of information accompanying each ITP work package inclusive of designs, monitoring results, test results, surveys etc.

Each ITP package had its own control document that was signed off at required stages of the design implementation to confirm compliance. The ITP control document for each design was, on completion, signed by the quality manager, the mine manager, and ultimately signed off by the independent verifier post review completion. There were over 400 separate ITP packages in the rehabilitation program. An indicative ITP folder structure is shown in Figure 3. 


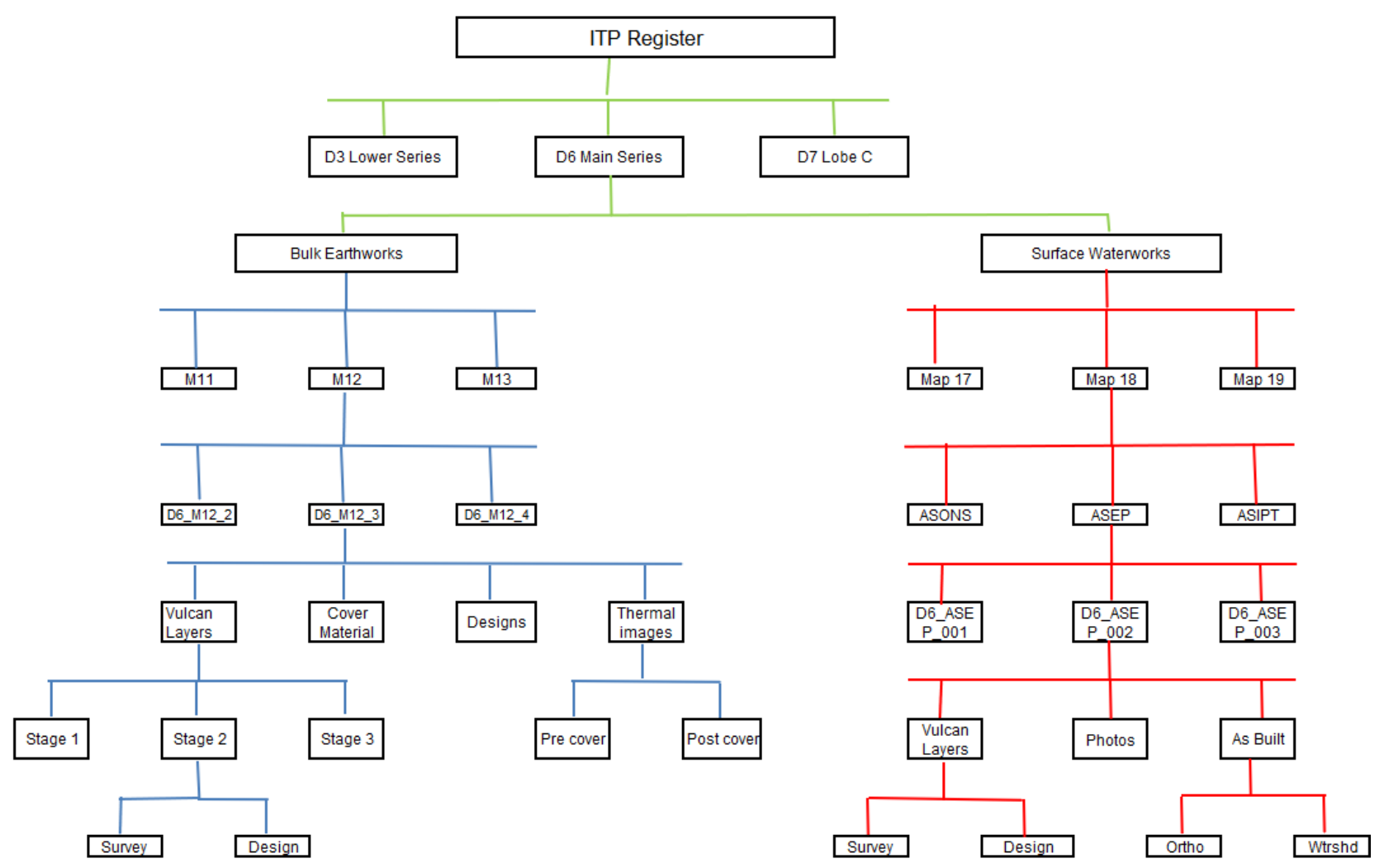

Figure 3 Indicative Inspection Test Plan (ITP) folder structure

\section{Unmanned aerial vehicle system}

The UAV utilised to capture survey data during the design and verification process was a fixed wing Quest Q200 survey pro, Figure 4 . This system was chosen for its durability, modular design, high wind tolerance and flight capabilities. The Quest Q200 has a flight speed of 35 knots and a long flight time of approximately 1 hour. Data was captured using a gimbled Sony A6000 24 MP camera with post processed kinematic (PPK) functionality and ground control to create accurate and detailed digital terrain models (DTMs) and georeferenced ortho-mosaic images. Accuracy tolerance expected for this system is $\pm 50 \mathrm{~mm}$ (with $95 \%$ confidence intervals). A total of 2,500 line $\mathrm{km}$ were flown during the Leigh Creek MCP project.

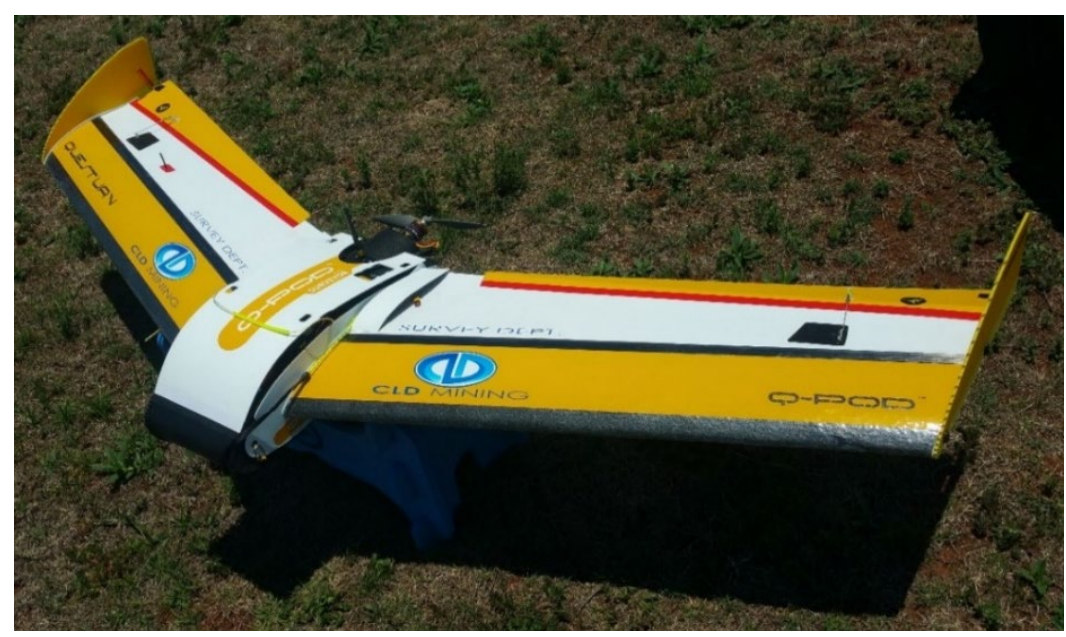

Figure 4 Quest Q200 survey pro 


\section{$7 \quad$ Bulk earthworks}

As can be seen in the indicative view of the ITP data file structure displayed in Figure 3, there are two distinctively different ITP package types, bulk earthworks and surface water control.

The procedural control, data capture and QA/QC for the reprofiling and covering of the surface and in-pit waste dumps is captured by the bulk earthworks ITP. A flow chart of the bulk earthworks ITP is shown in Figure 7. The three stages of the operational workflow are shown on the right-hand side along with the stop/hold points where a compliance with design sign-off by the responsible party was required before work could progress to the next stage.

\subsection{Waste dump face profiling (Stage 1)}

Stage 1 of the bulk earth works program was to re-profile the in-pit and surface waste dump faces. The natural repose angle of $37^{\circ}$ dump slopes were designed to have a 1:4.5 grade as displayed in Figure 5. The reprofiled surface was designed by cross-sections at $20 \mathrm{~m}$ intervals along the strike of the waste dump to create the crest (cut) line and the toe (fill) line. The cross-sectional area of the cut was designed to equal the fill (with a reduction of $10 \%$ due to the additional compaction via dozer of the fill material).

Original slope

Re-profiled slope

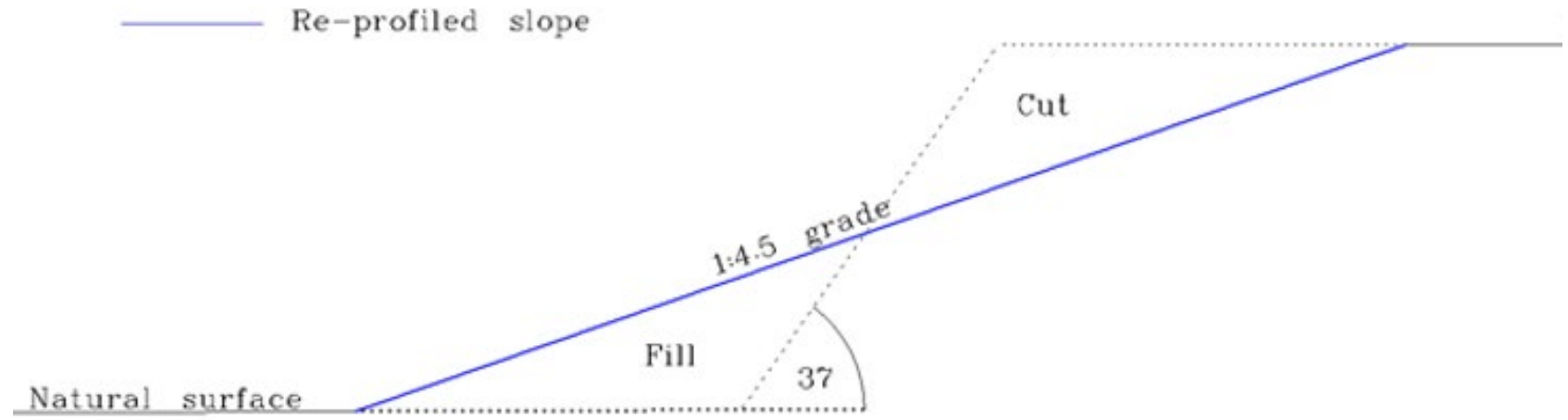

Figure 5 Dump slope re-profile design example

Once the stage 1 reprofiling had been completed, a hold point in the ITP was in place until surveyed and the grade verified to be equal to or greater 1:4.5 as in Figure 6. If the desired grade was not achieved, a plan indicating the location of the non-conforming slope was provided to site personnel. Once amendments to the slope were finalised, the area was re-surveyed and stage 1 in the ITP document signed as completed.

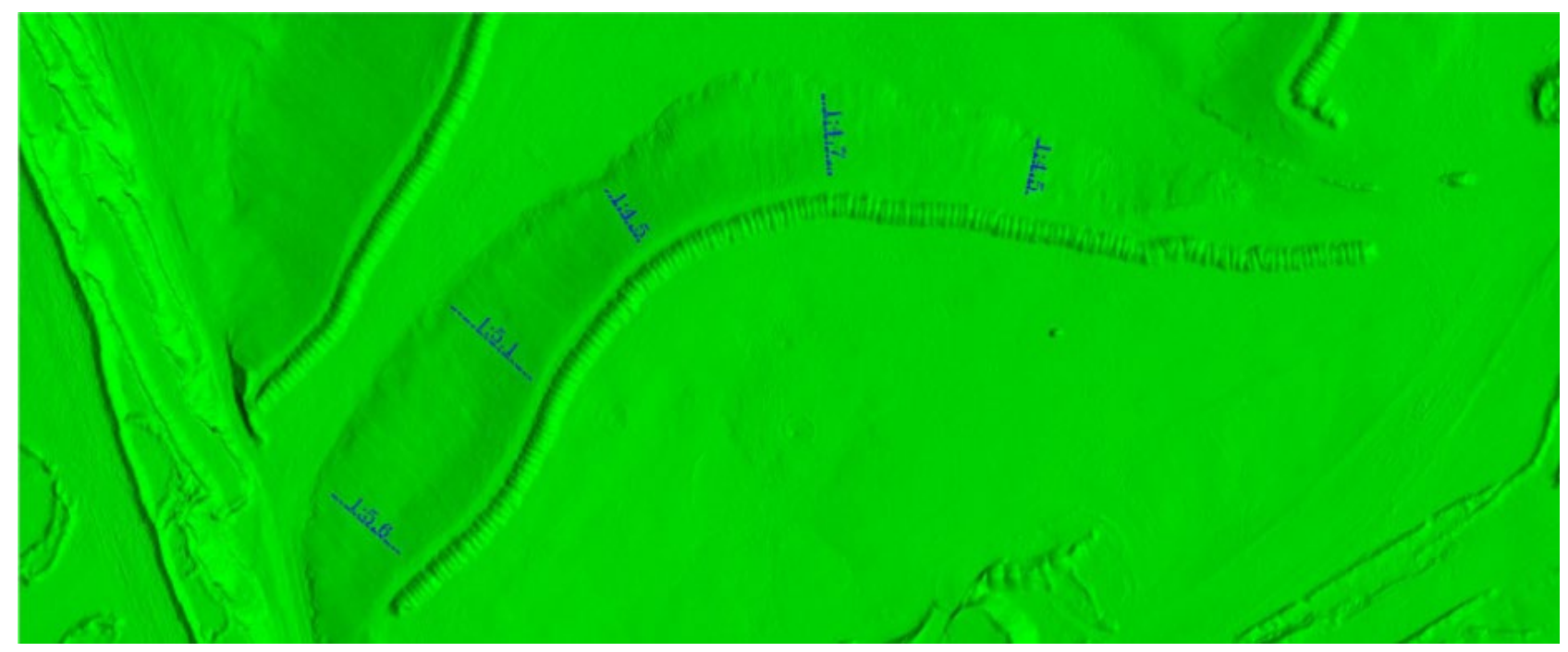

Figure 6 Profiled surface grade check example 

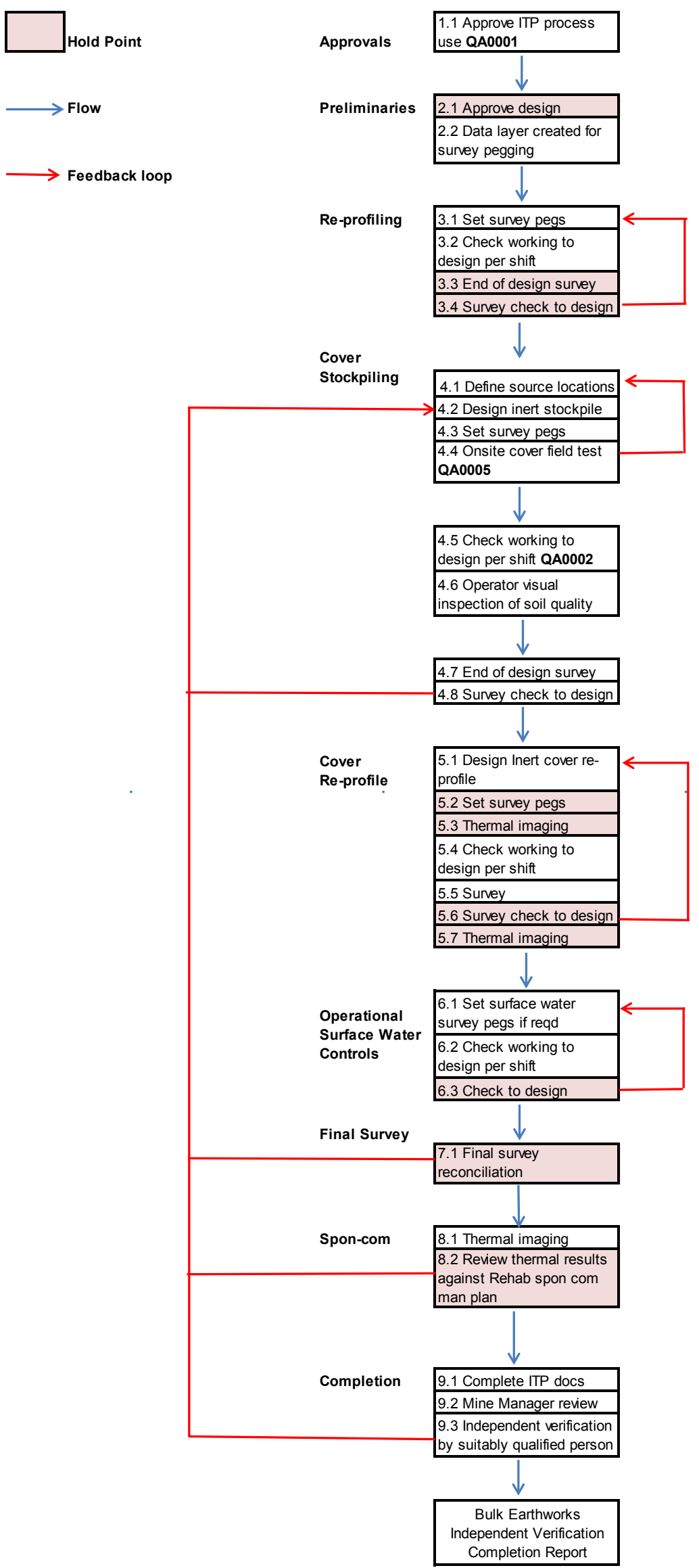

QA0001

QA0002

QA0005

TP Master form

Daily production Sign off

Cover Material verification sheet

Stage 1 - Reprofile

Stage 2 - Inert cover

Stage 3 - Cover reprofiling

Thermal imaging

Independent review

Figure 7 Inspection Test Plan (ITP) bulk earthworks flow chart 
High-resolution geo-referenced images were created at each stage of the bulk earthworks and surface water ITP process for visual verification of works completed. Figure 8 is an example of stage 1 image for waste dump slope D6_M7_1.

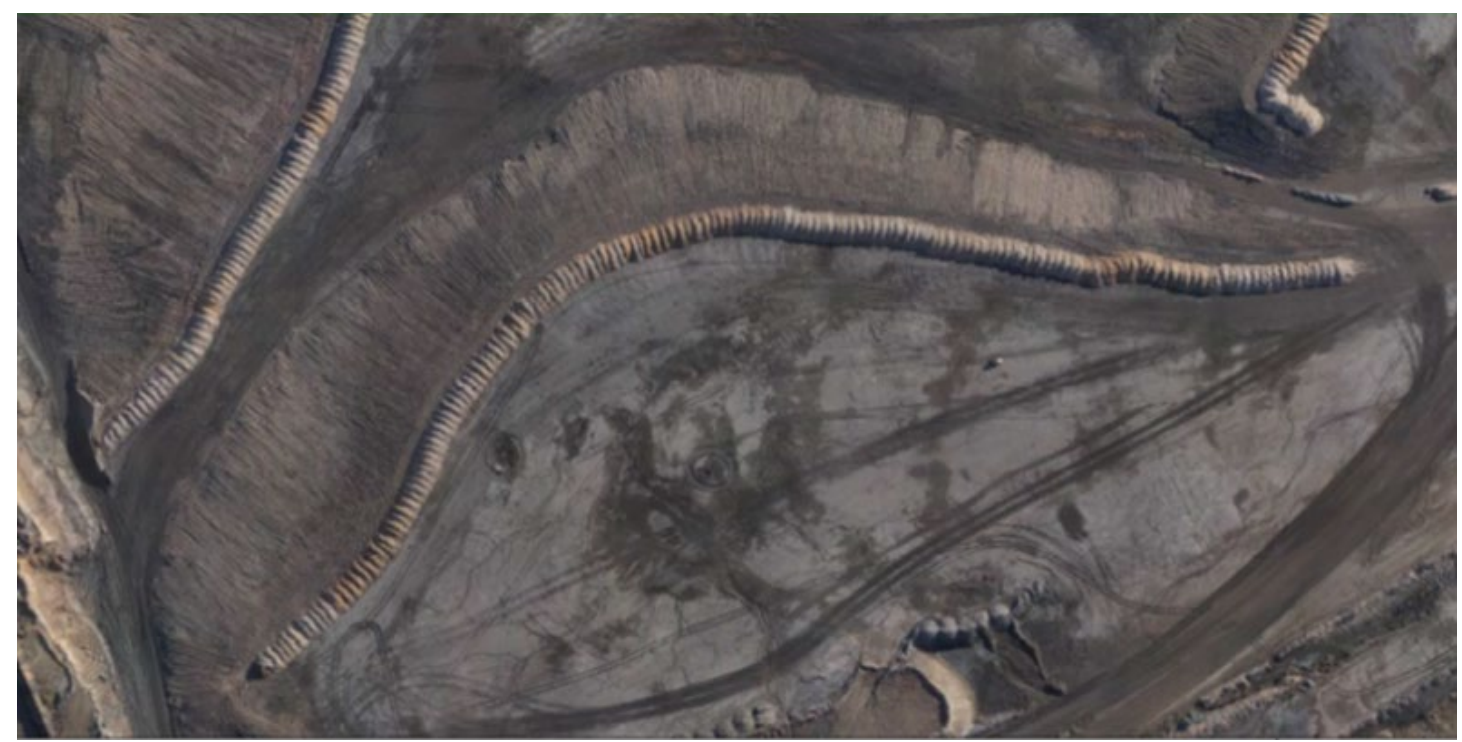

Figure 8 High-resolution image of D6_M7_1

\subsection{Inert material haulage (Stage 2)}

As a result of the sampling and laboratory testing program, conducted during the MCP development (MWH Stantec 2017), an inert material movement plot was created to illustrate the inert cover material sources, volumes and planned destinations, this is illustrated in Figure 9.

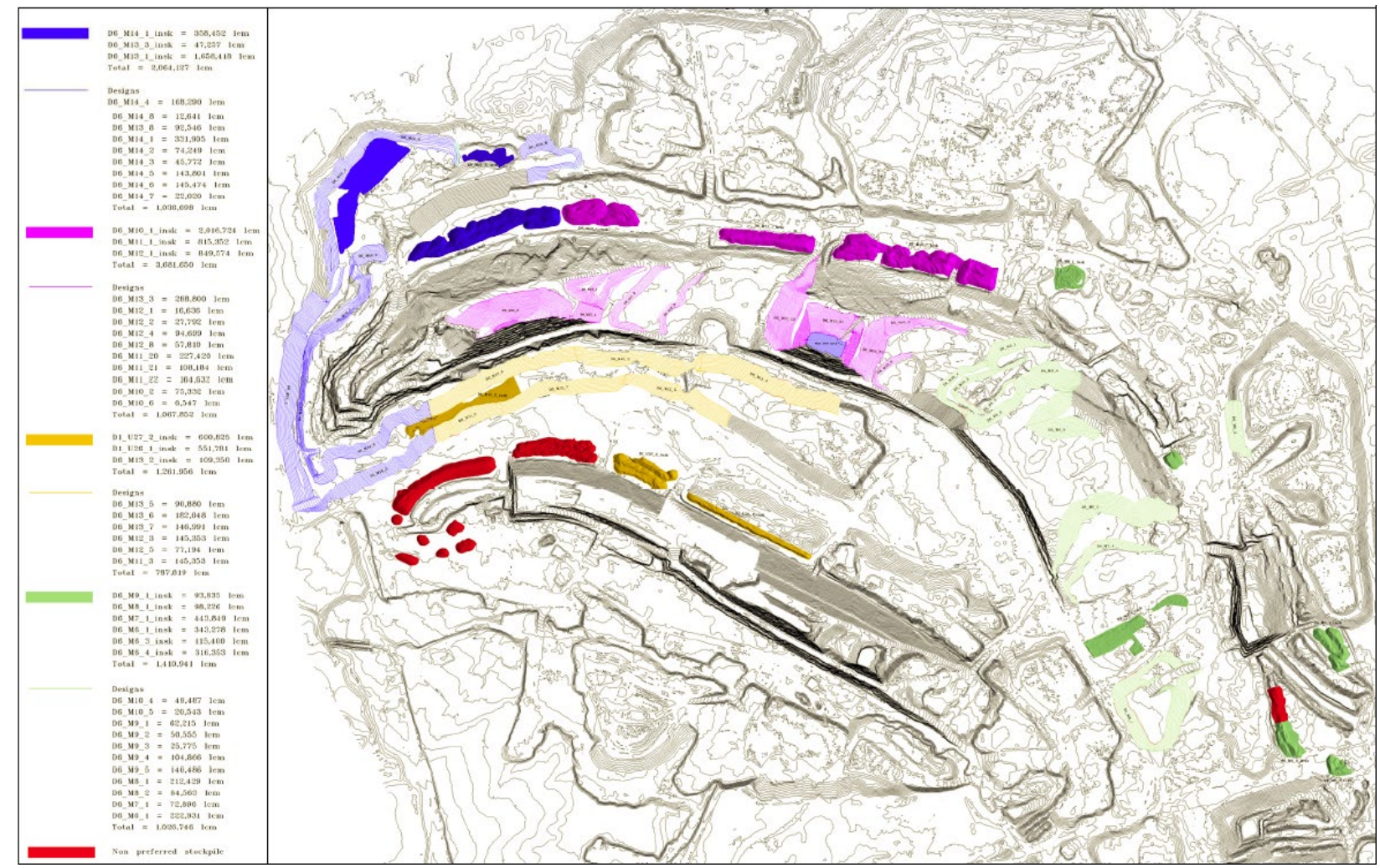

Figure 9 Inert material movement plot, source stockpiles are dark with corresponding destination represented by lighter contoured design 
With technical help from MWH Stantec, an onsite field sampling and analysis protocol was developed. The objective of the process was to collect real-time information to ensure the cover material selection was in accordance with the established material selection criteria as detailed in the MCP, and to identify and quarantine potentially hostile materials as they are uncovered within the selected cover stockpiles.

The data from the onsite field testing, confirmatory laboratory testing, and consultant review relevant to each design area was captured in a cover material verification file as part of each ITP folder. A sign-off to confirm compliance with the cover material selection requirements for each ITP was a key requirement.

The onsite field testing process entailed three core elements:

1. The training of machine operators to identify and de-select potentially hostile materials.

2. Progressive field-based sampling of inert material stockpiles, and field-based testing of:

○ $\mathrm{pH}$ (saturated paste).

- Electrical conductivity (saturated paste).

- Emerson dispersion test.

3. One in ten of the field samples were sent for confirmation laboratory testing to ensure compliance with the full cover material specification as detailed in the MCP.

The stage 1 aerial survey of the reprofiled waste dump was used to determine the inert material dump toe line, to optimise the volume of material that had to be hauled. Cross-sections were created in $20 \mathrm{~m}$ intervals to determine the correct dump toe position. The inert material cross-sectional area had to be equal to the cross-sectional area of a $1.2 \mathrm{~m}$ true thickness cover. Compaction testing indicated a $20 \%$ compaction rate was achieved while profiling the inert material (Coffey Environments 2017).

The required cross-sectional area of the inert cover stage 2 dump was increased by $20 \%$ to accommodate for dozer compaction of the inert material, Figures 10 and 11 . Once the stage 2 inert material haulage had been completed, a hold point in the ITP was in place until surveyed and verified. Any shortage of inert material was calculated and identified on a plan and provided to operational personnel for additional haulage.

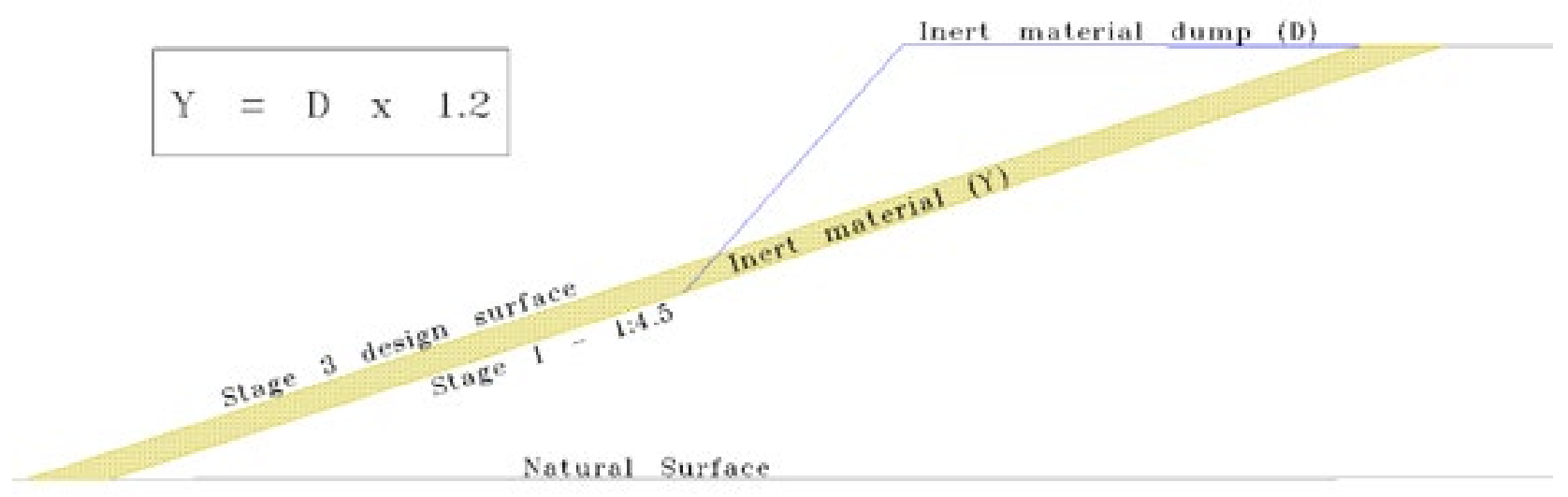

Figure 10 Cross-section - surveyed inert material dump and profiled waste dump. Inert material cross-sectional area $(Y)=$ Inert material dump cross-sectional area (D) multiplied by 1.2 


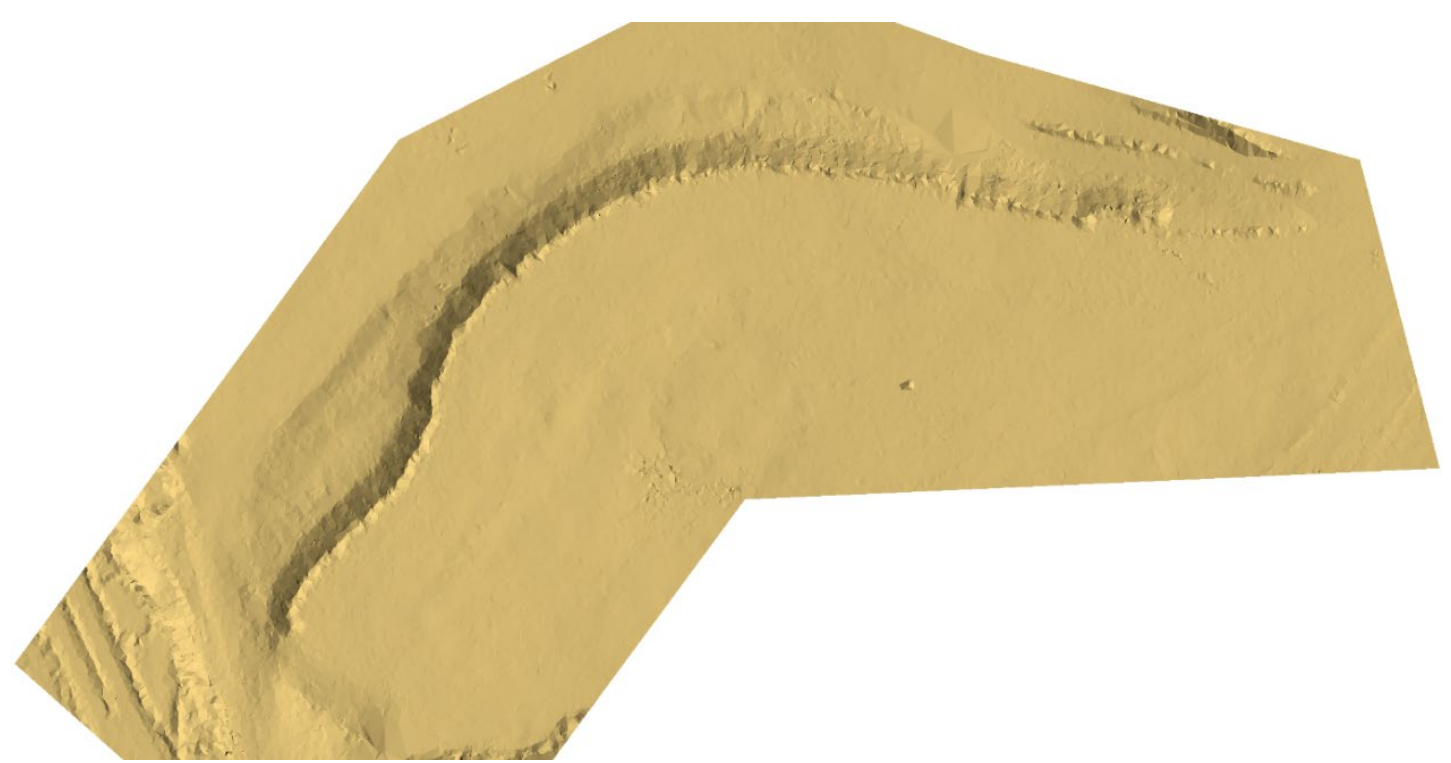

Figure 11 Stage 2 aerial survey for D6_M7_1

\subsection{Inert material cover profiling (Stage 3)}

As per Flinders Power (2018a) the dumped inert material was required to be reprofiled to a 1:4.5 grade with a $1.2 \mathrm{~m}$ true thickness to reduce the risk of spontaneous combustion of the waste material. Using the stage 2 aerial survey, $20 \mathrm{~m}$ cross-sections were created of the dumped inert material. The designed inert material profile surface (stage 3 ) was created based on the actual inert material dumped (stage 2) to compensate for potential cover material over dumping as displayed in Figure 12. Therefore, the surface was designed using the surveyed cross-sectional area of the inert material dump not just the projected (stage 1) surface, and then imported into the dozer GPS system.

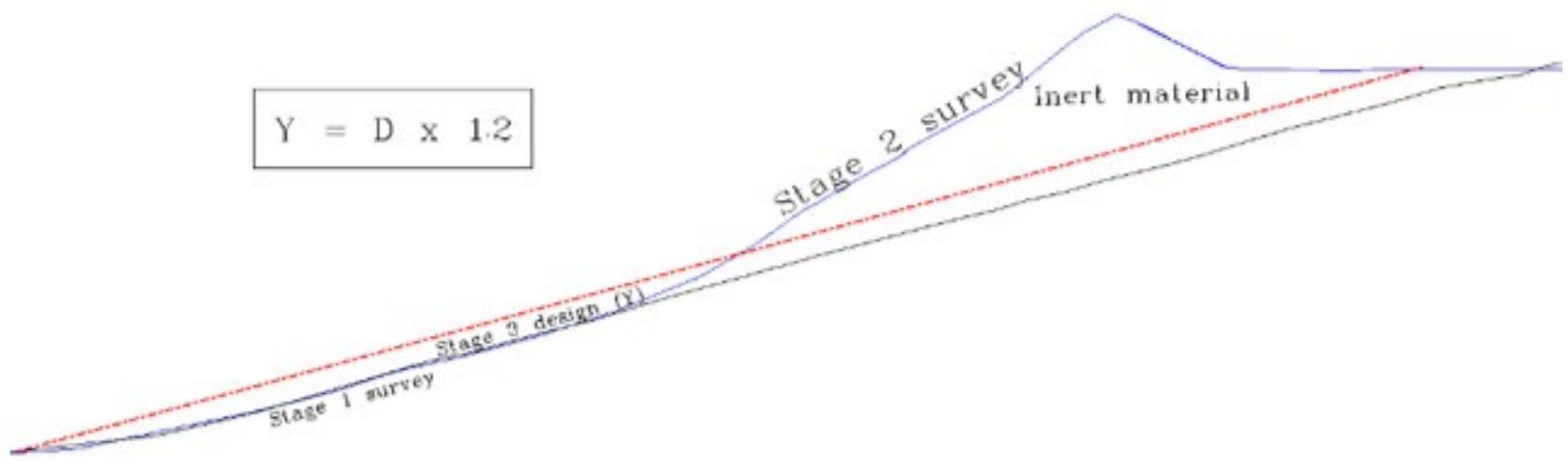

Figure 12 Stage 3 cross-section design for D6_M7_1. Inert material cross-sectional area $(y)=$ inert material dump cross-sectional area (D) multiplied by 1.2

Once the inert material had been profiled, a hold point in the ITP was in place until the slope was surveyed and inert material true thickness verified. Using the survey data of stage 1 and stage 3 , a thickness grid ( $1 \mathrm{~m}$ by $1 \mathrm{~m}$ grid) was created to verify the inert cover true thickness (Figure 13). 


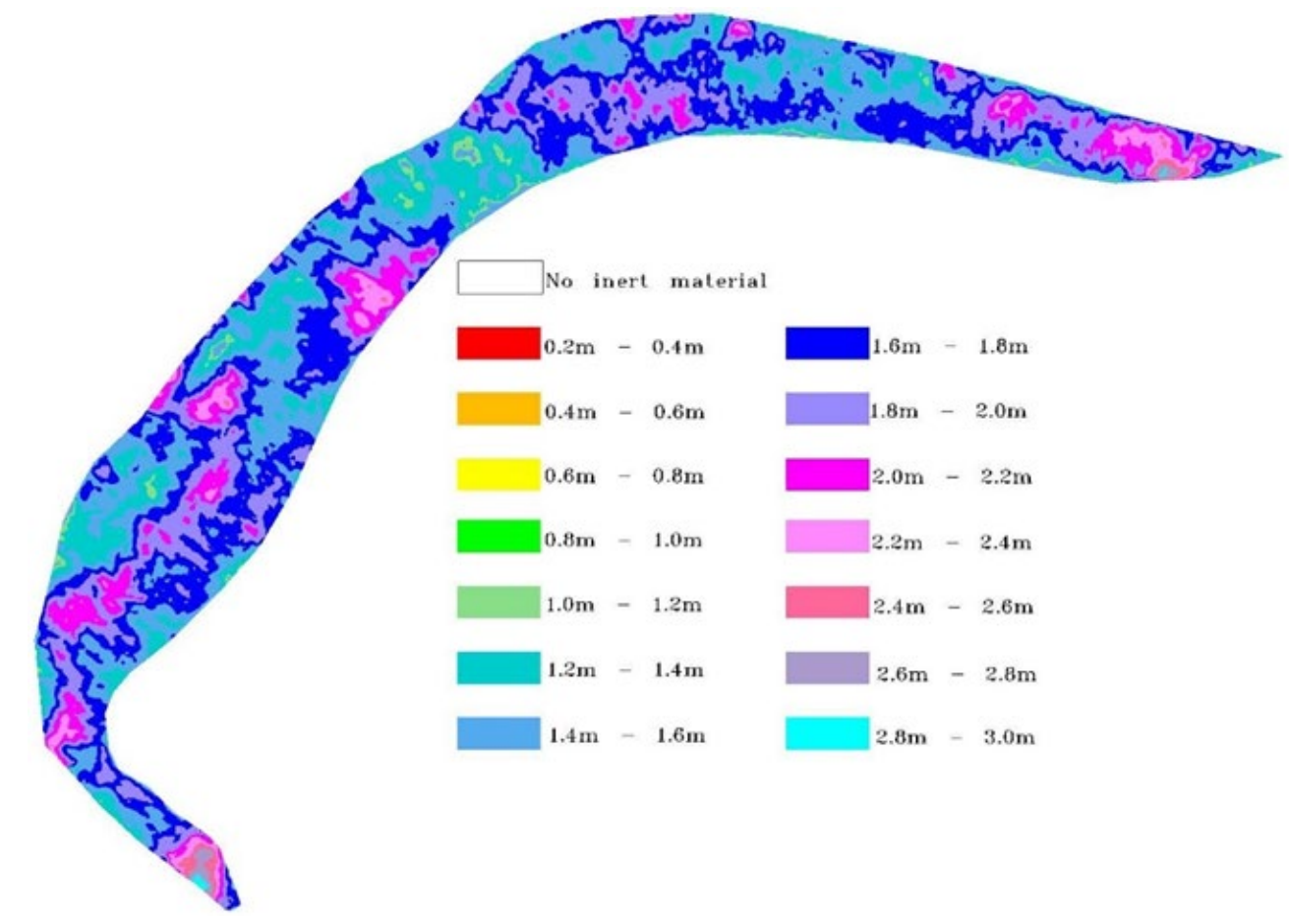

Figure 13 Inert material thickness grid example

If the inert material thickness grid identified non-conforming areas, they were identified on a thickness grid map and provided to operational personnel to correct. In addition, polygons of the shortfall areas were created and sent to the site surveyor for pegging. Once amended the waste dump slope was re-surveyed and a thickness grid created to confirm.

\section{Surface water control works}

The Leigh Creek Coalfield (Lobe B) surface water management plan was split into seven sub-catchment categories:

- ASEP (Above Surface Evaporation Pond).

- NSEP (Nat Surface Evaporation Pond).

- IPEP (In-Pit Evaporation Pond).

- IPT (In-Pit Transfer).

- NSIPT (Nat Surface In-Pit Transfer).

- ASIPT (Above Surface In-Pit Transfer).

- ASOS (Above Surface transferred Offsite).

In this document, we will discuss the watershed analysis of the evaporation ponds (ASEP, NSEP and IPEP).

A total of 293 evaporation ponds were designed and constructed for the surface water management plan. Evaporation ponds were designed to capture rainfall during a $100 \mathrm{yr} / 72 \mathrm{hr}$ rainfall event. The UAV platform was used to survey the evaporation ponds and a watershed analysis was completed to verify the catchment will withstand the designated rainfall event.

When designing evaporation bunds different aspects of each sub-catchment were considered, these were:

- Catchment area size.

- Topography. 
- Material type.

- Spon comb history.

- Current surface water bund effectiveness.

- Evidence of tunnelling.

The volume of water for a $100 \mathrm{yr} / 72 \mathrm{hr}$ rainfall event was derived from historical local rainfall data from the Bureau of Meteorology. With the known sub-catchment area and the historical local rainfall event data a volume of water for each sub-catchment was inferred. Table 1 indicates rainfall event data for the Leigh Creek area. For a conservative approach to build in some additional contingency absorption of the dump material was assumed to be zero, in reality it would be expected that some absorption would occur.

Table 1 Leigh Creek historical rainfall data in $\mathrm{mm}$

\begin{tabular}{lcccccc}
\hline Duration & $\mathbf{2} \mathbf{y r}$ & $\mathbf{5} \mathbf{~ y r}$ & $\mathbf{1 0} \mathbf{~ r r}$ & $\mathbf{2 0} \mathbf{y r}$ & $\mathbf{5 0} \mathbf{~ r ~}$ & $\mathbf{1 0 0} \mathbf{~ r r}$ \\
\hline $5 \mathrm{~min}$ & 5 & 8 & 9 & 11 & 14 & 16 \\
$6 \mathrm{~min}$ & 6 & 8 & 10 & 12 & 16 & 18 \\
$10 \mathrm{~min}$ & 8 & 11 & 14 & 17 & 21 & 24 \\
$20 \mathrm{~min}$ & 11 & 17 & 20 & 25 & 31 & 36 \\
$30 \mathrm{~min}$ & 14 & 20 & 25 & 30 & 38 & 44 \\
1 hour & 18 & 26 & 32 & 39 & 50 & 58 \\
2 hours & 22 & 33 & 40 & 49 & 62 & 72 \\
3 hours & 24 & 36 & 45 & 55 & 69 & 81 \\
6 hours & 29 & 43 & 53 & 65 & 83 & 98 \\
12 hours & 34 & 52 & 64 & 79 & 100 & 117 \\
24 hours & 41 & 62 & 77 & 95 & 120 & 141 \\
48 hours & 49 & 73 & 90 & 111 & 141 & 165 \\
72 hours & 51 & 77 & 95 & 117 & 148 & 174 \\
\hline
\end{tabular}

\subsection{Watershed analysis}

Once the evaporation pond is constructed a hold point in the IPT is in place until surveyed and verified using a watershed analysis using Global Mapper ${ }^{\odot}$ software. The purpose of performing the watershed analysis is to verify the constructed evaporation pond capacity exceeds the expect $100 \mathrm{yr} / 72 \mathrm{hr}$ rainfall event volume.

Using Global Mapper ${ }^{\odot}$ software, the virtual water level is raised to find the first break point of the evaporation pond. To build in a $10 \%$ contingency to the bund height as agreed with the independent verifier, the virtual water level is then reduced by $30 \mathrm{~cm}$ to identify the maximum capacity level. The volume of water calculated from the maximum capacity level is compared to local historical data volume for the subcatchment (Table 1). If the maximum capacity is a higher than a $100 \mathrm{yr} / 72 \mathrm{hr}$ event, then the ITP is signed and completed for the sub-catchment.

For example, the total surface area for sub-catchment D6 ASEP 024 shown in Figure 14 is 11,348 $\mathrm{m}^{2}$, which includes the evaporation pond area and the dump slope to the south. Rainfall predictions in Table 2 would have a water inundation during a $100 \mathrm{yr} / 72 \mathrm{hr}$ rainfall event of $1,975 \mathrm{~m}^{3}$ for evaporation pond D6_ASEP_024. 


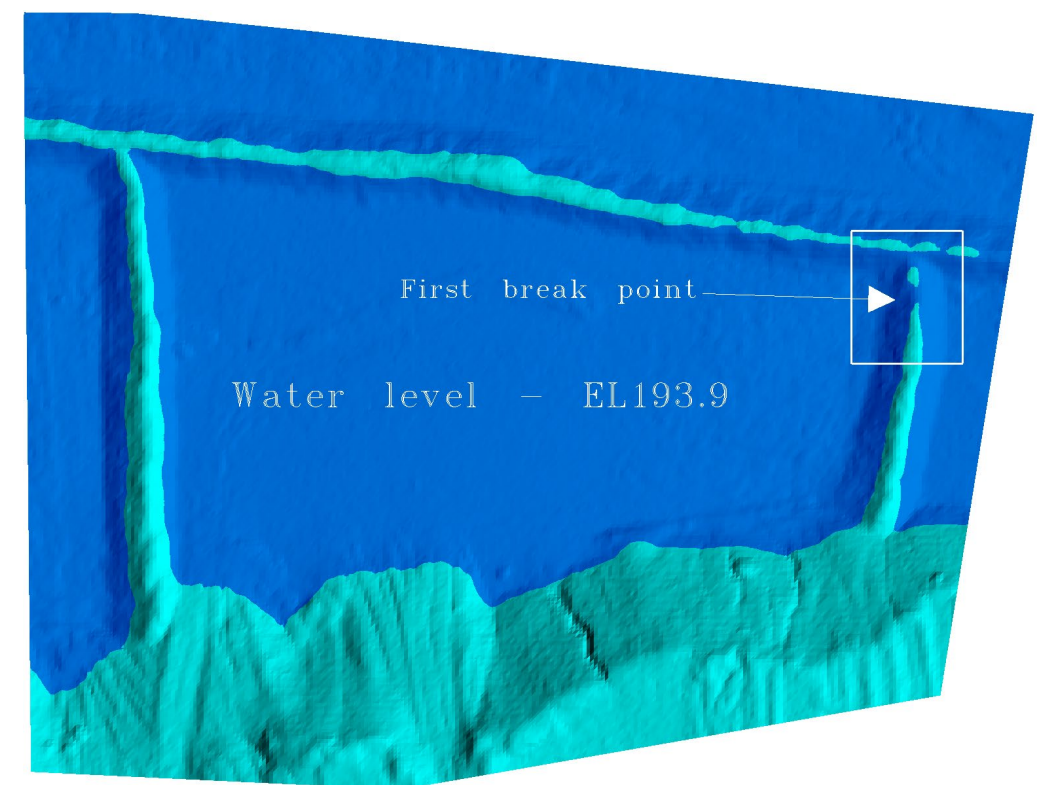

Figure 14 Watershed analysis D6_ASEP_024 first break point

Table 2 Inferred rainfall event volume $\mathrm{m}^{3}$ for sub-catchment D6_ASEP_024

\begin{tabular}{lcccccc}
\hline Duration & $\mathbf{2} \mathbf{~ y r}$ & $\mathbf{5} \mathbf{~ y r}$ & $\mathbf{1 0} \mathbf{~ r r}$ & $\mathbf{2 0} \mathbf{~ r r}$ & $\mathbf{5 0} \mathbf{~ r r}$ & $\mathbf{1 0 0} \mathbf{~ r ~}$ \\
\hline $5 \mathrm{~min}$ & 59 & 86 & 104 & 126 & 158 & 183 \\
$6 \mathrm{~min}$ & 65 & 96 & 116 & 141 & 176 & 203 \\
$10 \mathrm{~min}$ & 88 & 129 & 157 & 191 & 238 & 276 \\
$20 \mathrm{~min}$ & 128 & 188 & 229 & 280 & 351 & 409 \\
$30 \mathrm{~min}$ & 154 & 229 & 278 & 340 & 426 & 495 \\
1 hour & 202 & 300 & 365 & 447 & 563 & 655 \\
2 hours & 247 & 372 & 454 & 556 & 701 & 819 \\
3 hours & 275 & 412 & 507 & 623 & 786 & 919 \\
6 hours & 325 & 490 & 604 & 742 & 946 & 1,110 \\
12 hours & 386 & 586 & 722 & 893 & 1,135 & 1,328 \\
24 hours & 463 & 706 & 872 & 1,074 & 1,362 & 1,600 \\
48 hours & 550 & 833 & 1,024 & 1,260 & 1,600 & 1,872 \\
72 hours & 579 & 874 & 1,078 & 1,328 & 1,680 & 1,975 \\
\hline
\end{tabular}

As shown in Figure 14, the first break point at evaporation pond D6_ASEP_024 is EL193.9. The water level value was reduced to EL193.6, to derive the maximum water capacity and volume calculated to be $4,805 \mathrm{~m}^{3}$ as shown in Figure 15, in this example the capacity being more than twice the required 1,975 $\mathrm{m}^{3}$. 


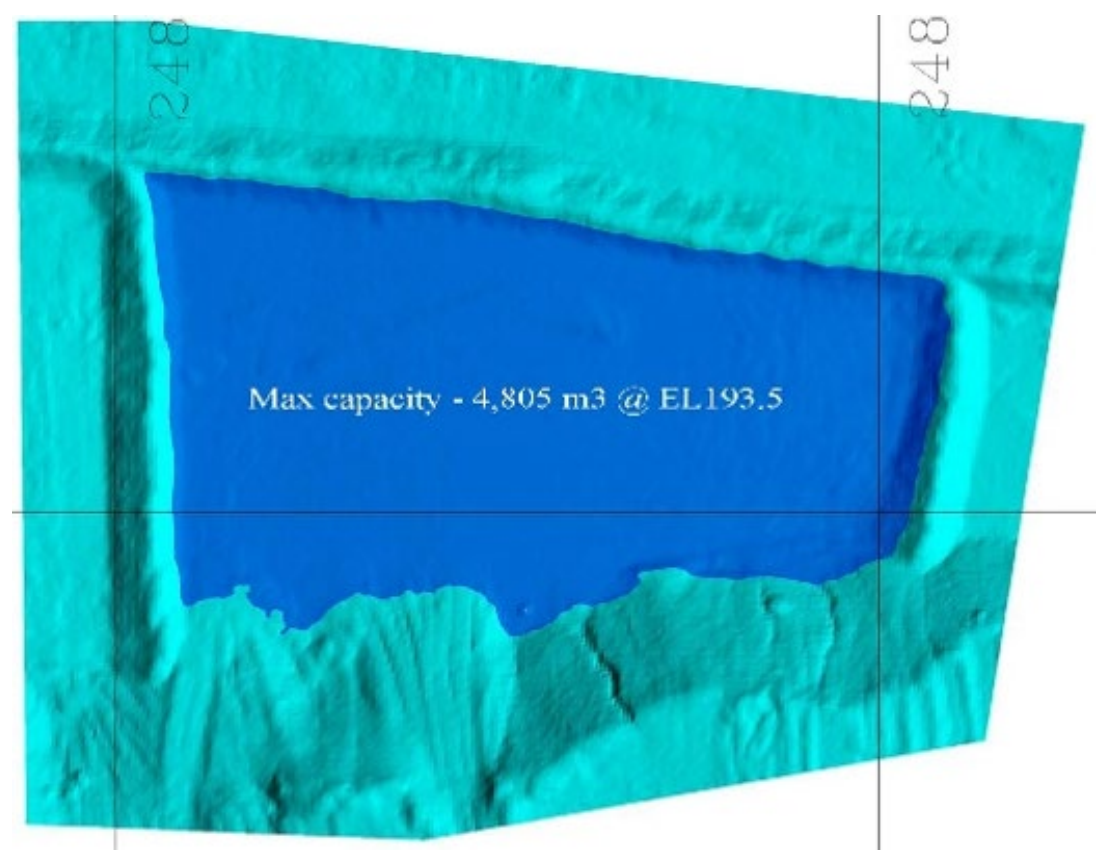

Figure 15 Final watershed analysis D6_ASEP_024

In the event of weak or low points in the bund being identified, a plot was provided to the site operations team for amendments. Once completed, the area was re-surveyed, and the ITP document signed and completed. Figure 16 is the completed ortho-mosaic plot for sub-catchment D6_ASEP_024.

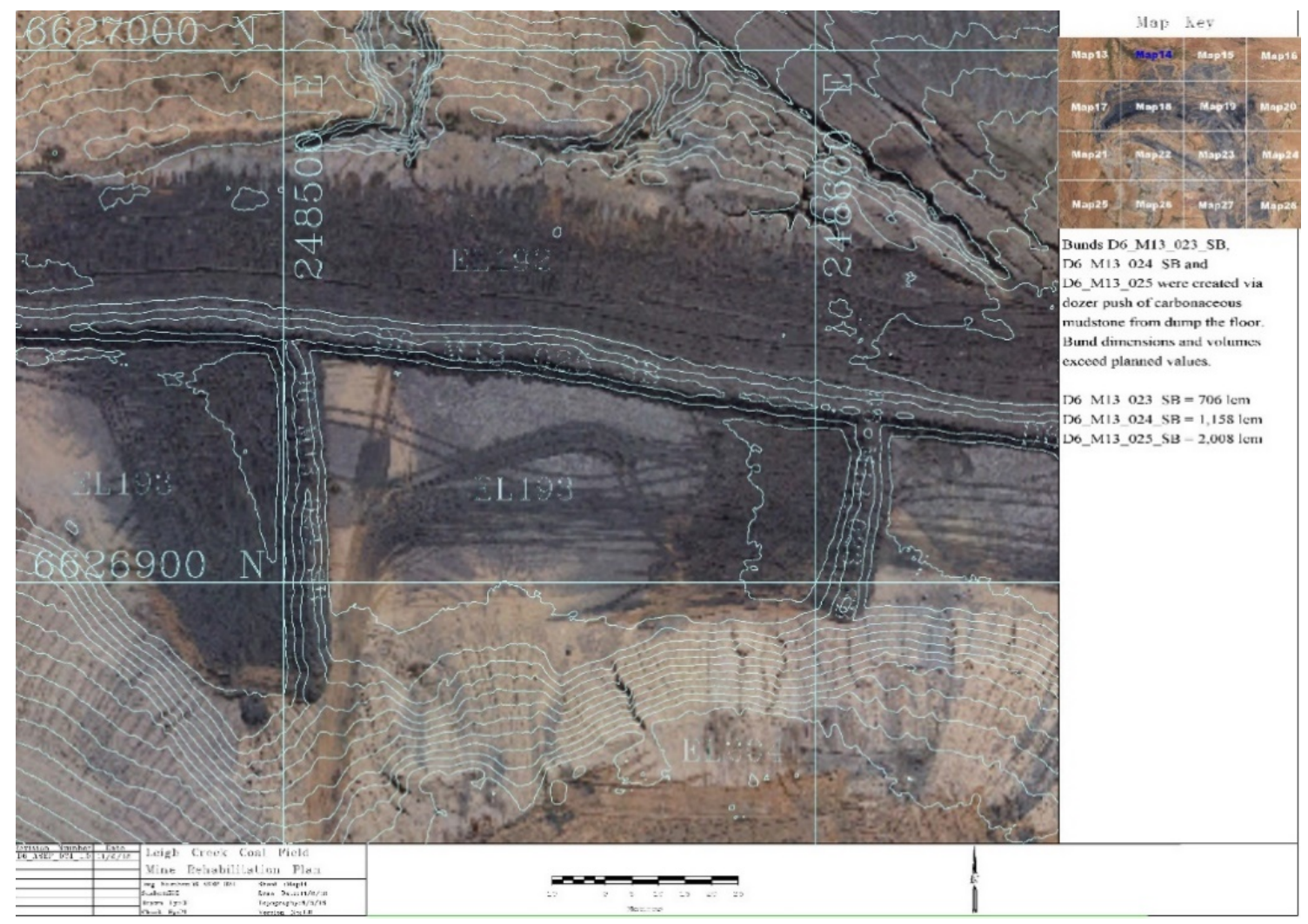

Figure 16 Final ortho-mosaic image D6_ASEP_024 


\section{Conclusion}

The ITP utilising state-of-the-art UAV technology enabled Flinders Power to control the implementation of the mine closure works program, ensuring each rehabilitated area met the design requirements at each step of the process. It was successfully employed to achieve independent verification of the detailed mine closure relinquishment criteria at Leigh Creek.

The volume of data involved in a mine closure project the size of Leigh Creek is immense. The ITP and the use of the UAV technology enabled it to be captured, reviewed and approved in a timely fashion. It also presented the required information externally for review in a structured format.

The ITP process was designed by individuals with operational backgrounds, aware of the need for it to gain onsite acceptance and support for successful implementation. The acceptance of, and buy into, the process by everyone involved is one of the key reasons for its success.

\section{Acknowledgement}

Flinders Power wish to thank all the independent consultants and regulators involved and particularly acknowledge the exceptional work of the Leigh Creek operational team and the contribution of Mike Slight.

\section{References}

Coffey Environments 2017, 24.48 Appendix VV - Geotechnical Field Tests and Discussion for the Capping at Field Trial Location Leigh Creek Mine Closure, Appendices PP to VV, Department for Energy and Mining, Adelaide, https://sarigbasis.pir.sa.gov.au/WebtopEw/ws/samref/sarig1/image/DDD/PEPR415204PPVV.pdf

Flinders Power 2018a, Leigh Creek Coalfields Mine Closure Plan, Department for Energy and Mining, Adelaide, http://www.energymining.sa.gov.au/minerals/mining/mines_and_quarries/leigh_creek_coal_mine

Flinders Power 2018b, 24.12 Appendix L - Risk Assessments and Relinquishment Criteria, Department for Energy and Mining, Adelaide, https://sarigbasis.pir.sa.gov.au/WebtopEw/ws/samref/sarig1/image/DDD/PEPR458491LQ.pdf

MWH Stantec 2017, 24.57 Appendix EEE - Cover and Rehabilitation Material Characterisation Report, Department for Energy and Mining, Adelaide, https://sarigbasis.pir.sa.gov.au/WebtopEw/ws/samref/sarig1/image/DDD/PEPR415204AAA-FFF.pdf 